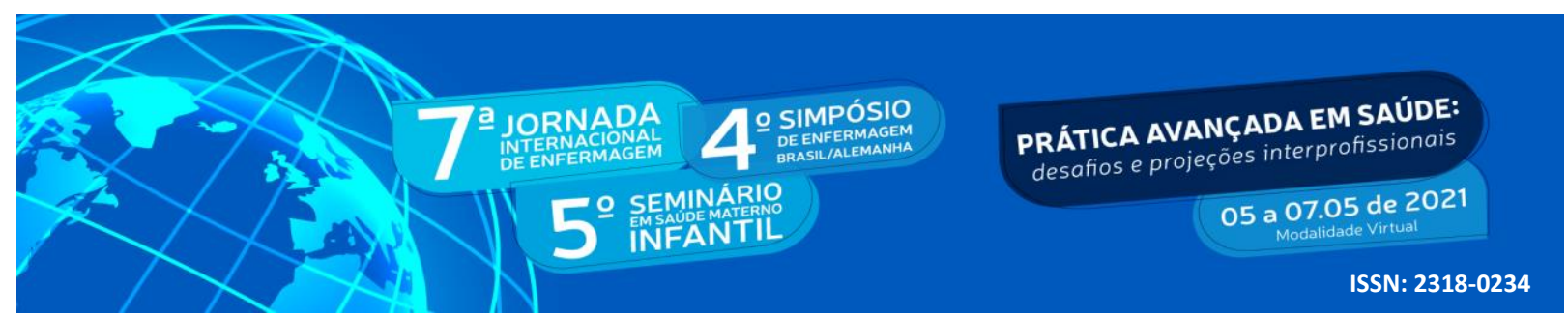

DOI: http://doi.org/10.48195/jie2021-041

\title{
INFLUÊNCIA E INTERFERÊNCIA DAS AVÓS NA GESTAÇÃO, PARTO E PUERPÉRIO: UM RELATO DE EXPERIÊNCIA ${ }^{1}$
}

\author{
Mariana Fogaça Martins²; Graziele Alves Flores ${ }^{3}$; Giovana Luiza Rossato ${ }^{4}$; Leandro da \\ Silva de Medeiros5; Naiana Oliveira dos Santos'; Maria Helena Gehlen ${ }^{7}$
}

\begin{abstract}
RESUMO
Objetivo: Descrever a experiência de estudantes de enfermagem quanto às influências e interferências das avós na gestação, parto e puerpério. Método: Trata-se de um estudo descritivo, do tipo relato de experiência, desenvolvido por discentes de enfermagem, a partir do preenchimento de um formulário on-line por uma gestante, uma avó e uma puérpera, no período de agosto a dezembro de 2020, no decorrer da disciplina de Atenção Integral a Saúde do Idoso. Resultados: A exposição centra-se em dois eixos temáticos: 1) Influências e Interferências das avós na gestação e parto; 2) Influências e Interferências das avós no puerpério e cuidados ao recém-nascido e criança. Conclusão: Conclui-se que a experiência demonstrou aos estudantes que as avós maternas participam ativamente no período gravídico puerperal de suas filhas. A experiência oportunizou ao grupo de estudantes observar as influências e interferências de avós, principalmente, nas questões fisiológicas da gestação e puerpério como azia, enjoo e amamentação.
\end{abstract}

Palavras-chave: Enfermagem; Gestação; Idosos; Puerpério; Saúde Materno-Infantil.

\begin{abstract}
Objective: To describe the experience of nursing students regarding the influences and interferences of grandmothers during pregnancy, childbirth and the puerperium. Method: This is a descriptive study, of the experience report type, developed by nursing students, from the completion of an online form by a pregnant woman, a grandmother and a puerperal woman, from August to December 2020 , during the course of Comprehensive Health Care for the Elderly. Results: The exhibition focuses on two thematic axes: 1) Influences and Interferences of grandmothers in pregnancy and childbirth; 2) Influences and Interferences of grandmothers in the puerperium and care for newborns and children. Conclusion: It is concluded that the experience demonstrated to the students that the maternal grandmothers actively participate in the postpartum pregnancy period of their daughters. The experience gave the group of
\end{abstract}

\footnotetext{
1 Relato de Experiência

${ }^{21}$ Estudante do Curso de Enfermagem. Universidade Franciscana. E-mail: marianaf.martins03@gmail.com

32 Estudante do Curso de Enfermagem. Universidade Franciscana. E-mail: flores.graziele8@gmail.com

$4^{3}$ Estudante do Curso de Enfermagem. Universidade Franciscana. E-mail: rossatogiovana@gmail.com

$5^{3}$ Estudante do Curso de Enfermagem. Universidade Franciscana. E-mail: leandro.medeiros@ufn.edu.br

6 Professora. Doutora em Enfermagem. Universidade Franciscana. E-mail: naiana.santos@ufn.edu.br

74 Orientadora. Doutora em Enfermagem. Docente do Curso de Enfermagem da Universidade Franciscana -

UFN. E-mail: gehlenmh@gmail.com
} 


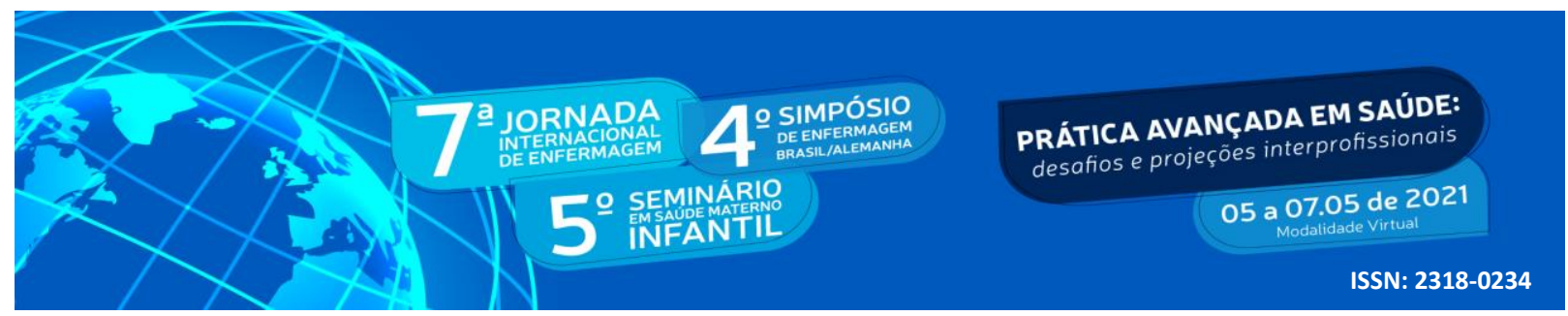

students the opportunity to observe the influences and interferences of grandparents, mainly in the physiological issues of pregnancy and the puerperium such as heartburn, nausea and breastfeeding.

Key Words: Nursing; Pregnancy; Elderly; Puerperium; Maternal and Child Health.

\section{INTRODUÇÃO}

O processo de envelhecimento é considerado um desenvolvimento individual, irreversível e natural de todas as espécies. Demonstrando ser uma população com crescimento expressivo e evoluções significativas na qualidade de vida. Trazem consigo uma bagagem singular e manifestam as subjetividades em suas ações com as demais pessoas. Sendo contextualizadas, conforme as condições socioeconômicas, culturais e étnicas de cada um (GAMELEIRA et al, 2020).

Nesse contexto, muitos idosos têm forte influência e colaboração na vida dos seus filhos e netos. No momento em que eles adquirem o papel de avós, percebem-se como possíveis participantes em diversas condutas referentes ao binômio mãe-bebê. Assim, geralmente colocam em prática muitos de seus aprendizados, costumes populares e ensinamentos passados de geração para geração. Como também, relatando suas experiências próprias, no qual vivenciaram durante seu período gravídico-puerperal (SCREMIM; BOTTOLI, 2016).

Conforme Louzeiro e Lima (2017), a vida após a experiência de ser avó, é percebido com uma entoação de alegria, conforto, prazer em exercer esse papel, fonte de boas energias e renovação biológica. Sentindo-se responsáveis por cada momento vivenciado nesta fase e como uma poderosa ferramenta motivadora para a vida. Sendo referências da família para conselhos cautelosos e disciplina para todos.

Por conta disso, as influências das avós às gestantes e puérperas podem ser percebidas na prática de amamentação, como um fortalecimento cultural da família. Reforçando as condições nutricionais, afetuosas e protetivas relacionadas a tal prática. Bem como, participam ativamente nas escolhas das filhas quanto ao sustento nutricional dos bebês, em especial se possuírem contato direto com as mesmas. Configurando, assim, como um suporte de autoconfiança e aconchego nas relações interpessoais com suas filhas (DEUS; DIAS, 2016).

Diante do exposto, surge o seguinte questionamento: Quais são as influências e interferências das avós na gestação, parto e puerpério a partir da experiência de estudantes de 


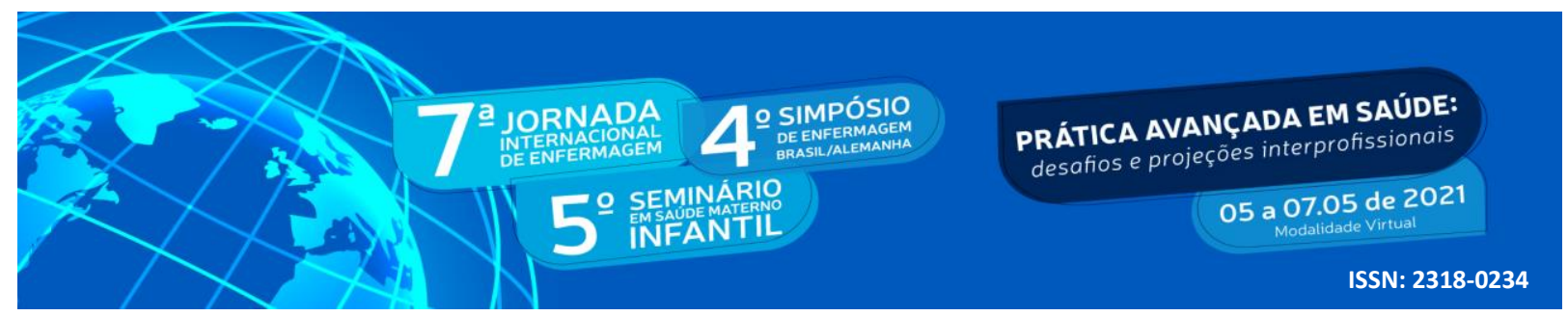

enfermagem?

\section{OBJETIVO}

Este estudo tem por objetivo descrever a experiência de estudantes de enfermagem quanto às influências e interferências das avós na gestação, parto e puerpério.

\section{METODOLOGIA}

Trata-se de um estudo descritivo, do tipo relato de experiência, desenvolvido por quatro discentes do curso de enfermagem de uma universidade privada da região central do Rio Grande do Sul. O estudo foi desenvolvido no período de agosto a dezembro de 2020, na disciplina “Atenção Integral à Saúde do Idoso", do curso de graduação em enfermagem, sob orientação da professora responsável.

O relato de experiência se traduz em texto acadêmico que descreve precisamente uma dada experiência que possa contribuir de forma relevante para sua área de atuação profissional. Caracteriza-se por uma vivência considerada importante para a formação dos futuros profissionais da área da enfermagem, em seu meio acadêmico e contribui com a discussão, análise e a proposição de estratégias para a melhoria do cuidado em saúde, saber popular e cuidado multidimensional (FERREIRA, 2019).

Para essa experiência, os alunos foram instigados a buscarem e conhecerem as evidências atuais sobre as influências das avós no período gravídico-puerperal. Dessa forma, buscou-se em base de dados artigos científicos sobre a temática. Após a leitura dos estudos, foi elaborado um formulário no Google Forms, com o intuito de conhecer as interferências e influências das avós e enviado à uma gestante, uma avó e uma puérpera de diferentes núcleos familiares.

O vídeo educativo, produzido pelos acadêmicos do grupo de trabalho, foi desenvolvido na plataforma Canva, utilizando-se imagens do Google imagem para demonstração de boas práticas. As informações contidas no material audiovisual foram extraídas de evidências científicas. Após a conclusão do dispositivo, o mesmo foi publicado no YouTube e nas mídias sociais Instagram e Facebook do Grupo Gestar (@grupo_gestar), onde concentra populares interessados na área da saúde materno-infantil. Salienta-se, que o estudo não foi enviado ao 


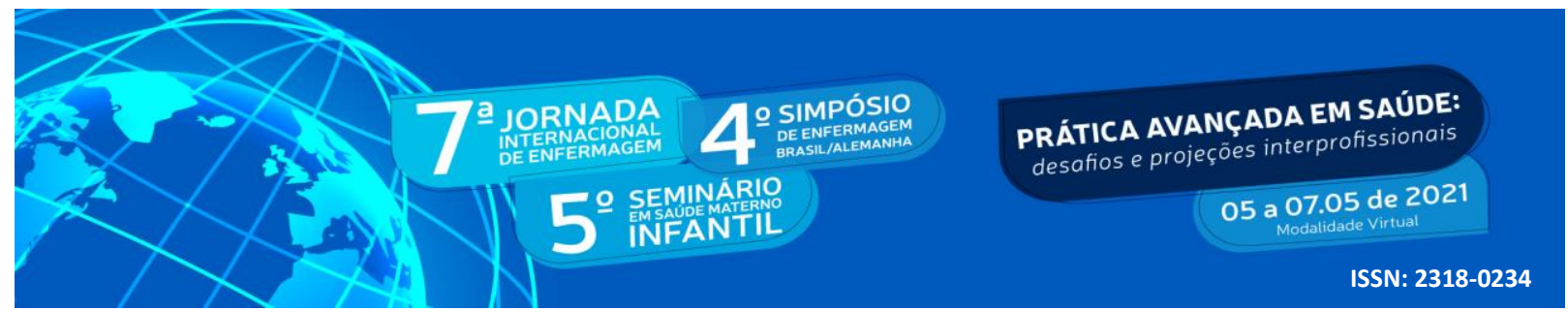

Comitê de Ética em Pesquisa (CEP). Nesse sentido, os resultados desse estudo serão traduzidos em forma de experiência.

Com base na síntese e análise das respostas e dos artigos científicos, o texto foi organizado em duas partes, com abordagem nas temáticas: "Influências e Interferências das Avós na Gestação e Parto" e "Influências e Interferências das Avós no Puerpério e Cuidados ao Recém-Nascido e Criança”.

\section{RESULTADOS E DISCUSSÃO}

Construiu-se dois eixos temáticos como guia de discussão denominados, conforme segue:

\subsection{Influências e interferências das avós na gestação e parto}

Com relação a temática da participação como avó no processo de gestação e puerpério do neto, compreendeu-se que a atuação principiou desde o primeiro momento da confirmação da gravidez. Considera que a sua presença permaneceu desde as primeiras roupas compradas por ela, para a chegada de seus netos. As avós acreditam que sua atuação se estabeleceu logo nas primeiras semanas de gestação.

Além disso, a atuação de maneira ativa possibilita sanar as dúvidas e o compartilhamento de práticas para a filha durante a gestação, pois durante o período de prénatal foi possível receber orientações quanto às práticas com o bebê por meio de rodas de conversas com mães, gestantes e puérperas. Bem como, as comunicações digitais contribuem de maneira positiva quanto às dúvidas geradas neste aspecto.

Tecnologias podem potencializar as consultas de enfermagem e empoderar as gestantes quanto ao autocuidado na gestação e puerpério. As participantes consideraram a ferramenta facilitadora e coadjuvante na construção e aprimoramento do conhecimento para as gestantes interessadas em qualificar o autocuidado durante a gestação (SILVA et al, 2017, p. 285).

Entretanto, o respeito e a autonomia permeiam entre mãe e filha acerca do tipo de parto a ser escolhido. A respeito da tomada de decisão da mãe, baseada nas orientações passadas pela avó na criação do seu filho, entendeu-se que a filha e nora predispõe de muita segurança e autoridade sobre as questões relativas ao cuidado e criação para com seu filho (a) durante a gestação. Em contrapartida, percebe-se que atualmente há uma forte influência da criação dos 


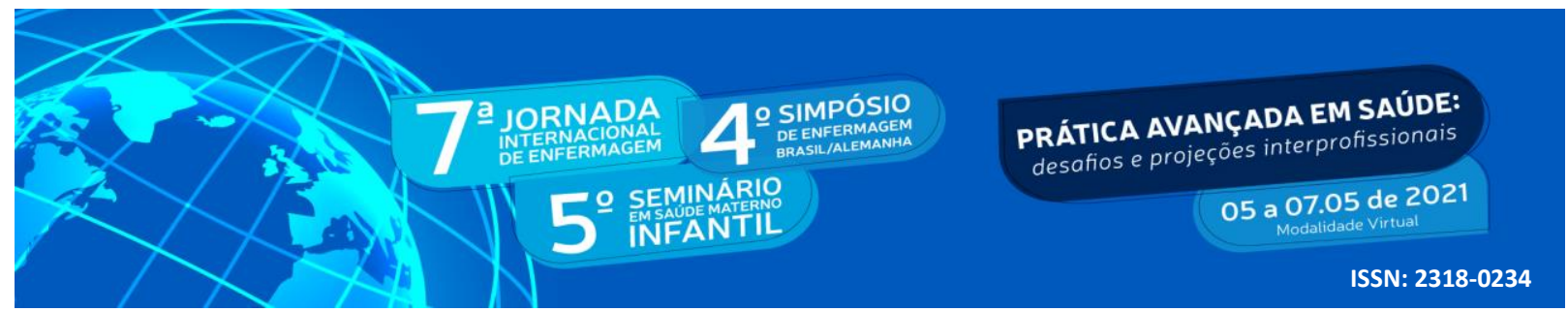

netos com relação ao modo de como os pais foram criados, ou seja, os filhos ainda criam de modo que foram criados.

O papel dos avós é bastante claro, assemelha-se ao dos pais, tanto dão afeto e carinho como repreendem quando necessário. Outros valores são passados através de conversas, orações, histórias de vida e brincadeiras. De entre algumas das contribuições dos mais velhos aos mais jovens verificamos a educação para o envelhecimento (SILVA, 2012, P. 67-75).

Relativamente ao seu papel de avó como influenciadora no processo de gestação e parto, é entendido que não mudaria nenhum quesito sobre suas atribuições como avó. Contudo a importância do livre arbítrio para que estes cuidados fossem exercidos pelos pais da criança, da qual também almejam que sua autoridade seja respeitada.

No ponto de vista da gestante, vislumbra-se que as influências das avós é algo positivo, pois apresenta-se como um apoio emocional, fonte de segurança e ajuda efetiva. Auxiliam com muita perspicácia em qualquer necessidade, como no preparo de alimentos ou sucos nutritivos para mantê-las sempre saudáveis. Tal como, as gestantes espelham-se nas futuras vovós como exemplos de mães que pretendem ser, visto que, sempre perceberam como um papel realizado com muito amor e dedicação.

As avós dispõem de fortes aspectos no quesito participação durante a gestação e puerpério. Por isso, percebeu-se no relato da gestante, as avós abrangem um envolvimento grande e muito prestativo em qualquer instante que for necessário. Percebendo-se como uma realização pessoal para elas, no qual terão efeitos assertivos na criação dos netos e assim obtendo maior segurança acerca das condutas tomadas quanto aos cuidados com seu filho (a).

Na perspectiva de suas ações como avó, as gestantes reconhecem que terão possíveis agrados perante sua neta, fazendo muitas de suas vontades e sem medir esforços para realizálos. Além disso, foi explicado pela gestante que a criação dos filhos seria muito diferente sem a presença direta da avó. Ressaltando que a distância deixaria ambas com muita saudade e sem a presença das trocas de afetos entre avó e neta. Como também, os cuidados prestados pela avó com sua neta, oportunizando condições mais favoráveis na vida pessoal e profissional da mãe, refletindo na organização de suas tarefas.

Percebe-se que as avós criam muitas expectativas para exercer esse papel, sentindo-se motivadas e com uma alegria extrema. Bem como, na elaboração de muitos planejamentos com a chegada do bebê na família. Também, é percebido o respeito da futura avó quanto às escolhas e posicionamentos relacionados ao bebê, não interferindo com opiniões e ideias próprias. 


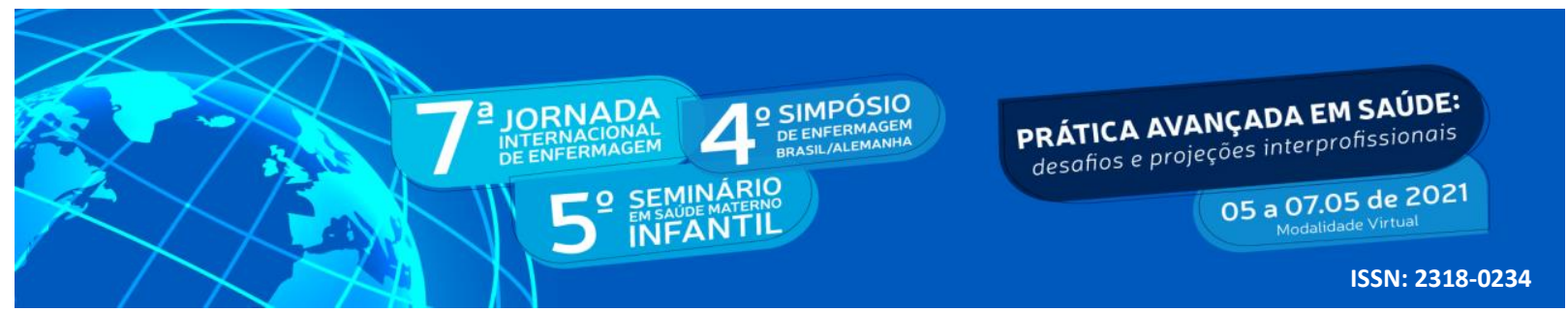

Deixando assim, sempre livre nas possibilidades quanto às condições de parto e aleitamento materno.

\subsection{Influências e interferências das avós no puerpério e cuidados ao recém-nascido e criança}

O período após o parto, chamado puerpério, é o momento em que ocorrem intensas modificações físicas e psicológicas nas mulheres num curto espaço de tempo. Juntas, essas características contribuem para aumentar a insegurança da mãe em relação aos cuidados necessários para garantir a saúde do seu bebê e dela própria nesta fase inicial da maternidade (BRASIL, 2015).

Dentre as inseguranças, destaca-se na amamentação, conhecimento acerca do aleitamento materno e cuidados com o coto umbilical. Nesse sentido, notou-se que as mães recorrem às avós para auxiliá-las nesse processo. Então, inicia-se o processo de interferência no puerpério, com uma bagagem de conhecimentos populares e culturas familiares. Por conta disso, na visão da puérpera no que tange o aleitamento materno, as avós influenciam e interferem com a inserção de chás e água.

A partir do conhecimento popular, as orientações oferecidas pela avó quanto a eventuais cólicas acometidas no bebê, foram sobre massagens na barriga e mantê-lo de bruços para o alívio. A mesma acredita que tais ações são eficientes facilitando rapidamente a melhora do quadro em que o bebê se encontra. Nos cuidados com o coto umbilical, foi analisado como os pais mantiveram plena autonomia e cautela para melhor cicatrização. Os pais utilizaram álcool $70 \%$ na técnica de cuidados com o cordão umbilical, não havendo nenhuma interferência por parte das avós.

Linhares (2012), descreve que o cuidado ao coto umbilical, pelas puérperas, é um ato que encontra respaldo na historicidade familiar, refletido na sua maneira de cuidar e envolve

os saberes culturais adquiridos intergeracionalmente, com maior influência dos membros familiares mais próximos.

Nesse sentido, os saberes culturais também refletem no aleitamento materno exclusivo. Sabe-se que não é necessário ser ofertado água, chá, papinha etc., nos primeiros seis meses. Por isso, a avó consegue reconhecer os benefícios do aleitamento materno e suas interferências cautelosas com comidas e bebidas na amamentação do RN. A Organização Mundial da Saúde, 


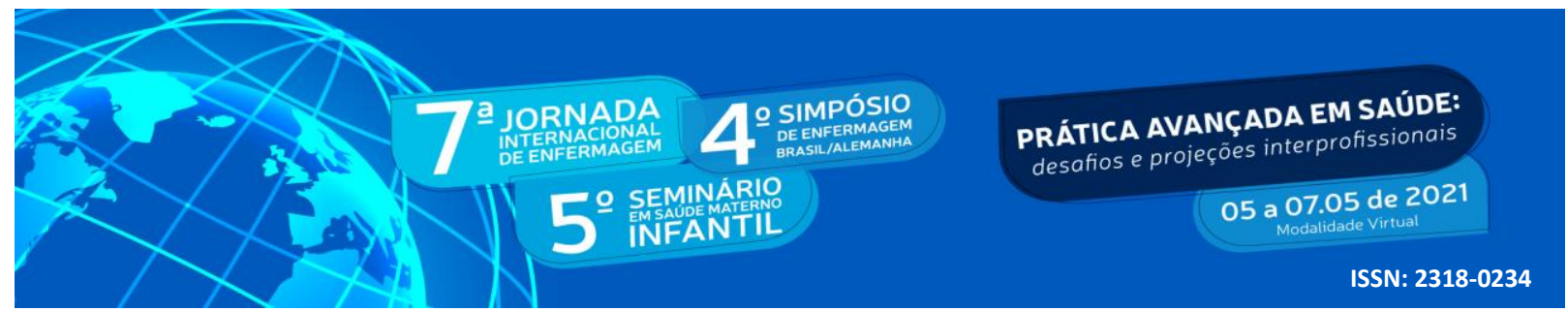

endossada pelo Ministério da Saúde, recomenda a amamentação por dois anos ou mais, sendo exclusiva nos primeiros seis meses de vida do bebê (MEDEIROS, 2020).

Do ponto de vista biológico, o leite materno é uma combinação única de ingredientes e apresenta menor densidade energética e maior teor de carboidratos em relação ao leite de outros mamíferos. Usando como comparação a composição do leite de vaca, que é a base usada no preparo da maioria das fórmulas infantis, são identificadas quantidades insuficientes de vitamina $\mathrm{E}$, ferro e ácidos graxos essenciais e quantidades excessivas de calorias, proteínas, potássio e sódio. Por isso, crianças com introdução precoce ao leite de vaca estão mais propensas a apresentar anemia e outras carências nutricionais (OLIVEIRA et al, 2016, p. 83).

No que se refere ao processo de desfralde dos netos, é revelado as influências desse processo. Sendo demonstrado com segurança ao adaptar-se de maneira mais rápida ao desuso das fraldas. A retirada de fraldas é um momento de aprendizagem social na vida das crianças em que deve haver respeito à sua autonomia, numa situação que possui interdependência com as culturas locais e requer a presença de um olhar pedagógico. Ao ser vista dessa maneira, tornase um gesto curricular que une corpo, cognição, cultura e emoção na educação infantil (BARBOSA; QUADROS, 2017).

\section{CONCLUSÃO}

Conclui-se que a experiência demonstrou aos estudantes que as avós maternas participam ativamente no período gravídico puerperal de suas filhas. A experiência oportunizou ao grupo de estudantes observar as influências e interferências de avós, principalmente, nas questões fisiológicas da gestação e puerpério como azia, enjoo e amamentação.

Apesar do papel importante que as avós desempenham na vida de uma criança, firmando uma relação intrafamiliar com a chegada do bebê, a ancestralidade que cada família carrega por meio da experiência de ser mãe, perpassa nos cuidados, na educação, nas tradições, saberes populares e no desenvolvimento da criança. Devemos considerar também, que através deste estudo, pode-se constatar que as gestantes e a puérperas como protagonistas da maternidade.

Deste modo, verifica-se que independente da atuação ativa ou não das avós no processo maternal, existe indubitável importância desta influência com as gestantes e puérperas, e o vínculo que se estabelece por meio das flexibilidades e oportunidades neste aspecto. No que concerne a experiência das avós no período gravídico-puerperal, percebe-se como uma perspectiva motivadora em sua vida, exercida com muita gratidão e entusiasmo. Por esse motivo, é aconselhável regularizar e estimular as trocas entre avós e gestantes, para que assim, o bem-estar de ambas seja fortalecido. 


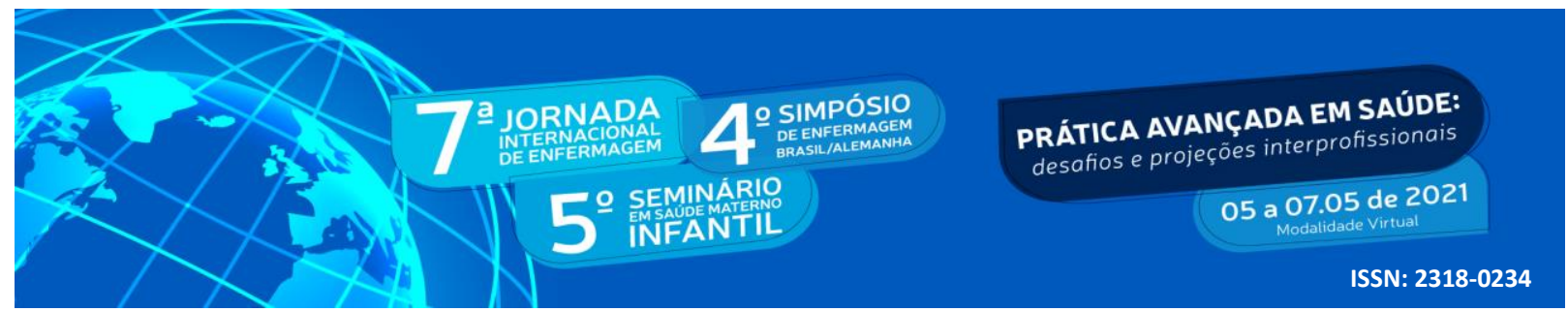

Por fim, a produção audiovisual, serviu como um produto de alto impacto nas redes sociais com teor de apresentar e educar famílias acerca das influências e interferências das avós na gestação, parto e puerpério. Ressalta-se que, não deve-se utilizar o presente estudo para conduzir práticas clínicas-assistenciais, por se tratar de uma dada experiência.

\section{REFERÊNCIAS}

BRASIL. Ministério da Saúde. Puerpério: O período pós-parto requer cuidados especiais. Blog da Saúde: Saúde da Mulher. 2015. Disponível em: http://www.blog.saude.gov.br/promocao-da-saude/50212-puerperio-periodo-pos-parto-requercuidados-especiais Acesso em: 27 nov. 2020.

BARBOSA, C.M.S.; QUADROS, V.S.R. As aprendizagens cotidianas: os cuidados pessoais das crianças como gesto curricular. Em aberto. v. 30, n. 100, p. 45-70, set./dez. 2017. Acesso em: 27 nov. 2020.

DEUS, M.D.; DIAS, A.C.G. Avós Cuidadores e Suas Funções: Uma Revisão Integrativa da Literatura. Pensando fam., Porto Alegre, v. 20, n. 1, p. 112-125, jul. 2016 . Disponível em: http://pepsic.bvsalud.org/scielo.php?script=sci_arttext\&pid=S1679494X2016000100009\&lng =pt\&nrm=iso. Acesso em: 28 nov. 2020.

FERREIRA, E. C.. Relatos de Experiência. Projeto de Pesquisa de conclusão de Especialização em Atenção ao Paciente Crítico: Urgência, Emergência e UTI (UNINTER). 2019.

GAMELEIRA, G. DE S. A.; MARQUES, L. F. S.; SILVA, D. D. DA; CARVALHO, C. M. R. G. DE. A bela velhice. Revista de Educação Popular, Uberlândia, v. 19, n. 3, p. 228-243, 23 nov. 2020.Disponível em: http://www.seer.ufu.br/index.php/reveducpop/article/view/52704. Acesso em: 25 nov. 2020.

LINHARES, E. F. et al . Influência intergeracional no cuidado do coto umbilical do recémnascido. Texto contexto - enferm., Florianópolis , v. 21, n. 4, p. 828836, Dec. 2012 Disponível em: http://www.scielo.br/scielo.php?script=sci_arttext\&pid=S0104-

07072012000400013\&lng=en\&nrm=iso. Acesso em: 27 nov. 2020.

LOUZEIRO, C. F. A; LIMA, A. B. R. Família e envelhecimento: um estudo sobre as relações entre avós e netos. Revista Ceuma Perspectivas, São Luís, MA, v. 30, n. 1, p. 132-149, mar./2017. http://www.ceuma.br/portalderevistas/index.php/RCCP/article/view/108. Acesso em: 28 nov. 2020. 


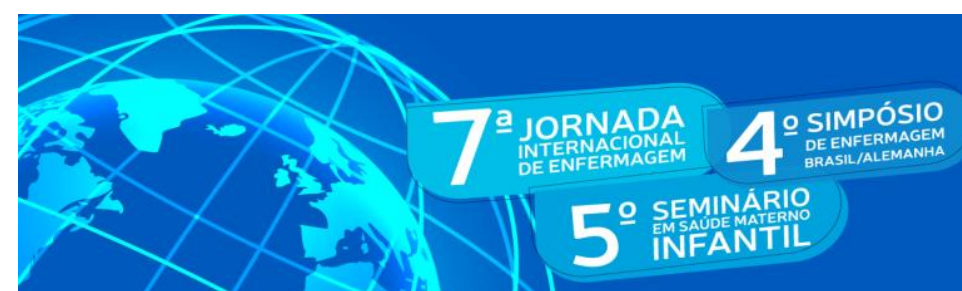

PRÁTICA AVANÇADA EM SAÚDE:

05 a 07.05 de 2021

ISSN: 2318-0234

MEDEIROS, L. S. Gestação, parto e nascimento na pandemia da COVID-19. Diário de Santa

Maria. $\quad$ p. 2,27 jul. $2020 . \quad$ Disponível em: http://https//diariosm.com.br/flip/view/?dataPublicacao=20200918\&publicacaoNome=Jornal\# page/2. Acesso em 30 nov. 2020.

OLIVEIRA, J. A. N. et al. A influência da família na alimentação complementar: relato de experiências. DEMETRA: Alimentação, Nutrição \& Saúde, [S.1.], v. 11, n. 1, p. 75-90, fev. $2016 . \quad$ Disponível em: https://www.epublicacoes.uerj.br/index.php/demetra/article/view/16053. Acesso em: 27 nov. 2020.

SCREMIN, A. L. X; BOTTOLI, C. Avós e netos: o exercício de uma parentalidade. Barbarói, Santa Cruz do Sul, v. 48, n. 48, p. 234-252, jul./2016. Disponível em:https://online.unisc.br/seer/index.php/barbaroi/article/view/5486. Acesso em: 28 nov. 2020.

SILVA, A. M. A colaboração dos avós na educação dos netos. Interfaces Científicas Educação, v. 1, n. 1, p. 67-75, set.2012. Disponível em: https://periodicos.set.edu.br/educacao/article/view/176. Acesso em: 27 nov. 2020.

SILVA, R. M. da et al . Mobile health technology for gestational care: evaluation of the GestAção's app. Rev. Bras. Enferm., Brasília , v. 72, supl. 3, p. 266273, Dec. 2019 Disponível em: http://www.scielo.br/scielo.php?script=sci_arttext\&pid=S0034$71672019000900266 \& \operatorname{lng}=$ en $\& n r m=$ iso. Acesso em: 27 nov. 2020 